\title{
Prevention of Fas-mediated hepatic failure by transferrin
}

\author{
Vladimir A Lesnikov ${ }^{1}$, Marina P Lesnikova ${ }^{1}$, Howard M Shulman ${ }^{1,2}$, Heather-Marie \\ Wilson $^{1}$, David M Hockenbery ${ }^{1,3,4}$, Markus Kocher ${ }^{5}$, Walter Pierpaoli ${ }^{6}$ and H Joachim \\ $\operatorname{Deeg}^{1,4}$
}

${ }^{1}$ Clinical Research Division, Fred Hutchinson Cancer Research Center, Seattle, WA, USA; ${ }^{2}$ Department of Pathology; ${ }^{3}$ Department of Gastroenterology; ${ }^{4}$ Department of Medicine, University of Washington, Seattle, WA, USA; ${ }^{5}$ IBR, Zürich, Switzerland and ${ }^{6} J e a n$ Choay Institute for Biomedical Research, Riva San Vitale, Switzerland

\begin{abstract}
Recent studies in lymphohemopoietic cells show that transferrin (Tf), a pivotal component of iron transport and metabolism, also exerts cytoprotective functions. We show here in a murine model that Tf interferes with Fasmediated hepatocyte death and liver failure. The mechanism involves the downregulation of apoptosis via BID, cytochrome $c$, caspase-3 and caspase-9, and upregulation of antiapoptotic signals via Bcl-xL. The results obtained with iron-saturated Tf, Apo-Tf and the iron-chelator salicylaldehyde isonicotinoyl hydrazone indicate that the observed antiapoptotic effect of Tf was not mediated by iron alone. In conclusion, the data suggest that Tf has broader functions than previously recognized and may serve as a cytoprotective agent.

Laboratory Investigation (2004) 84, 342-352, advance online publication, 5 January 2004; doi:10.1038/labinvest.3700035
\end{abstract}

Keywords: apoptosis; hepatocytes; fas signaling; transferrin; cytoprotection

Transferrin (Tf) is a ubiquitous protein with a central role in iron $(\mathrm{Fe})$ transport and metabolism. ${ }^{1,2}$ There is evidence, however, that in addition, Tf has profound effects on cell/cell interactions and cell integrity. ${ }^{3-5}$ We have shown in rodent, canine and human models that $\mathrm{Tf}$ interferes with programmed cell death induced via agonistic Fas signals, tumor necrosis factor alpha $(\mathrm{TNF} \alpha)$ and gamma-irradiation. ${ }^{6}$ The mechanism is not known but the fact that Tf mediated the effects across species barriers suggests a pathway preserved through evolution. In the present study, we used a murine in vivo model of Fas-mediated hepatocyte death ${ }^{7}$ to dissect the pathway(s) by which Tf exerts its cytoprotective effects.

The Fas receptor (Fas, APO-1, CD95) is highly expressed in the liver ${ }^{8}$ and serves as a central mediator of cell death under physiological and pathological conditions. $^{9-12}$ Ogasawara et $a l^{7}$ showed in a murine model that the injection of agonistic anti-Fas monoclonal antibody (mAb) with-

Correspondence: VA Lesnikov, Fred Hutchinson Cancer Research Center, 1100 Fairview Avenue North, D1-100, PO Box 19024, Seattle, WA 98109-1024, USA.

E-mail: vlesniko@fhcrc.org

Received 14 August 2003; revised 6 November 2003; accepted 13 November 2003; Published online 5 January 2004 in hours resulted in death from liver failure. There is some debate as to whether liver failure is induced via direct effects on hepatocytes or indirectly via endothelial cell injury and hemorrhage into the liver. ${ }^{13,14}$

Our results on the effect of exogenous Tf on Fasmediated hepatocyte death in the Ogasawara model ${ }^{7}$ in vivo, and in murine hepatocyte cell lines in vitro, show that Tf interfered with apoptosis, mitigated biochemical liver function abnormalities and prolonged survival in mice treated with otherwise lethal doses of agonistic anti-Fas mAb. The data suggest that $\mathrm{Tf}$ exerted its effect via a pathway that involves the upregulation of Bcl-xL and blockade of caspase-9 cleavage.

\section{Materials and methods}

\section{Animals}

Female BALB/c mice, 2-5 months old were purchased from Charles River (Hollister, CA, USA). Female C57BL/6J mice which were 2 months old, were purchased from Jackson Lab (Bar Harbor, ME, USA). Mice were used with the approval of the Institutional Animal Care and Use Committee and under National Institutes of Health guidelines. 


\section{Reagents}

Hamster anti-mouse Fas mAb (aFas) (clone Jo2, the NA/LE format), anti-cytochrome $c \mathrm{mAb}$ and rabbit polyclonal $\mathrm{Ab}$ to active mouse caspase-3 were purchased from PharMingen (San Diego, CA, USA). Antibodies to caspase-8 were obtained from Chemicon (Temecula, CA, USA). Mouse anti-human Tf-receptor mAb (anti-CD71 MAB clone 42/6) was provided by Dr. I.S.Trowbridge (The Salk Institute for Biological Studies, San Diego, CA, USA). Antibodies to caspase-10, caspase-3, cleaved caspase-3 (D175), BID, caspase-9 and Bcl-xL were obtained from Cell Signaling Technology (Beverly, MA, USA). Secondary horseradish peroxidase (HRP)-conjugated goat anti-rabbit IgG and rabbit anti-mouse IgG-HRP were purchased from Pierce (San Francisco, CA, USA). Human Tf was isolated and purified as described ${ }^{3}$ from blood plasma pooled from 2500 to 3000 normal donors (Sclavo Inc., Siena, Italy). In some experiments human $\mathrm{Tf}$ or mouse $\mathrm{Tf}$ from Sigma (St Louis, MO, USA) were used. All Tf preparations were endotoxin 'free' as determined by LAL technique at the Biologics Production Facility at the FHCRC (endotoxin content: human pooled Tf (Sclavo), 0.07-0.12 ng/mg; human Tf (Sigma), $0.07 \mathrm{ng} / \mathrm{mg}$; mouse Tf (Sigma), $1.5 \mathrm{ng} / \mathrm{mg}$ ). Human serum albumin (HSA; endotoxin content less than $0.1 \mathrm{ng} / \mathrm{mg}$ ) was purchased from Sigma and from Fluka (Milwaukee, WI, USA). Salicylaldehyde isonicotinoyl hydrazone (SIH), an iron chelator capable of iron delivery when saturated with iron $(\mathrm{FeSIH}),{ }^{15}$ was a gift from Dr Ponka (McGill University, Montreal, Canada). Rabbit anti-actin antibody was purchased from Sigma.

\section{Experimental Protocols in Mice}

aFas was injected once intraperitoneally (i.p.) in a volume of $0.25 \mathrm{ml}$ at doses ranging from 5 to $25 \mu \mathrm{g}$ per mouse. Tf was injected i.p. or intravenously (i.v.) repeatedly (two (24 and $1 \mathrm{~h}$ before aFas injection) or four times $(48,24$ and $1 \mathrm{~h}$ before, and $1 \mathrm{~h}$ after aFas injection)) in volumes of $0.25 \mathrm{ml}$ at doses of $0.05-$ $1.0 \mathrm{mg} / \mathrm{mouse}$ as indicated. Control animals received identical volumes of saline or corresponding doses of HSA preparations i.p. or i.v.

\section{Biochemical Liver Function Parameters}

Blood samples were obtained from retro-orbital sinuses of the mice under light halothane anesthesia 3 and $8 \mathrm{~h}$ after lethal and nonlethal doses of antiFas mAb, respectively. Aspartate-aminotransferase (AST), alanine-aminotransferase (ALT) and total bilirubin (TBIL) in murine plasma were determined spectrophotometrically at Phoenix Central Laboratory (Everett, WA, USA). Lactate dehydrogenase (LDH) was measured by using LDN-L Tris System
Pack (Boehringer Mannheim, Germany) at Ani Lytics Lab (Gaithersburg, MD, USA).

\section{Liver histology}

Liver tissue was fixed in $10 \%$ formalin and embedded in paraffin. Sections $(4 \mu \mathrm{m})$ were stained with hematoxylin/eosin, or prepared for terminal deoxynucleotidyl transferase and nick translation end labeling assay (TUNEL) or for immunohistochemical analysis to identify apoptotic hepatocytes in situ. TUNEL staining for determination of individual apoptotic cells ${ }^{16}$ was performed with the In Situ Cell Detection Kit according to protocol (Boehringer Mannheim, IN, USA).

\section{Immunohistochemistry for Active Caspase-3}

\section{Ex vivo}

Tf or saline pretreated mice were killed $3 \mathrm{~h}$ after lethal doses of aFas injection, and blood samples and liver tissue were harvested. Formalin-fixed, paraffin-embedded organ sections were stained with rabbit polyclonal antibodies directed at active mouse caspase-3 (Cleaved Caspase-3 Ab, Cell Signaling Technology, \#9661). Biotinylated goat antirabbit antibody was added as a second step, and HRP-conjugated streptavidin as a third step. Staining was visualized with $\mathrm{DAB} / \mathrm{NiCl}_{2}$ chromogen. As a negative control, staining was performed without primary antibodies. Immunostaining was quantitatively assessed using a $\times 20$ optic with a $10 \times 18$ ocular with an internal reticule surrounding a field size of $0.26 \times 0.18 \mathrm{~mm}^{2}$. The assessed field was determined by placing the portal space, and when present, central vein in the center of the field. At least 10 fields of each slide sample were counted.

\section{In vitro}

$\mathrm{NMH}$ cells were maintained ${ }^{17}$ and treated with $\mathrm{Tf}$ and anti-Fas MAB as described below. Cells were harvested at different time points after the addition of anti-Fas MAB onto 12-well adhesive slides (Fisher, Pittsburgh, PA, USA), fixed with acetone and stained with purified rabbit polyclonal antibodies directed at active mouse caspase-3 (Pharmingen, cat \# 67341A). Biotinylated goat anti-rabbit antibody was added as a second step and HRPconjugated streptavidin as a third step. Staining was visualized with $\mathrm{DAB} / \mathrm{NiCl}_{2}$ chromogen. As a negative control, staining was performed without primary antibodies.

\section{Preparation of Liver Tissue and Proteins}

Total body perfusion of euthanized mice via the left ventricle and open right atrium of the heart was performed with phosphate-buffered saline (PBS) to wash out blood from the liver. Slices of liver tissue 
were then snap-frozen in liquid nitrogen and stored at $-70^{\circ} \mathrm{C}$ until use. Triton X-100 lysis buffer ${ }^{18}$ and Chaps Cell Extract Buffer (Cell Signaling Technology) were used for liver tissue and blood plasma lysate preparation. After centrifugation at $10000 \mathrm{~g}$ for $10 \mathrm{~min}$, the supernatants were kept at $-70^{\circ} \mathrm{C}$ until analysis.

\section{Western Blots}

\section{Tf}

Quantitative anti-Tf Western blots were performed with serum albumins and plasma Tf as standards. Proteins separated on gels were transferred onto a PVDF membrane and immunodetected with goat anti-human Tf antibody (Sigma) and secondary alkaline phosphatase-conjugated anti-goat antibody.

Caspase-8 and 10, BID, Bcl-xL, cytochrome C, caspase-9 and caspase-3

Cell and plasma extracts were subjected to SDS gel (12\%) electrophoresis and immunoblot analysis. The amount of protein was estimated using BioRad Protein Assay and equal amounts of protein (20$40 \mu \mathrm{g}$ ) were loaded in each lane. The proteins were electrophoretically transferred onto an immunoblot PVDF membrane (BioRad) and blocked with 5\% nonfat dry milk in PBS/0.05\% Tween-20 (PBS-T) for $1 \mathrm{~h}$ at RT. Membranes were incubated with primary antibody diluted in 5\% BSA/PBS-T overnight at $4^{\circ} \mathrm{C}$ and washed three times with PBS-T. The blots were then incubated with HRP-conjugated secondary antibody for $1 \mathrm{~h}$ at RT in $2.5 \%$ BSA/PBS-T. Protein was detected using enhanced chemoluminescence reagents and CL-Xposure film (Pierce, Rockford, IL, USA). Differences in protein expression were determined by Western blot and densitometry analysis using 1.62 NIH Image.

\section{Cell Lines}

The nontransformed murine hepatocyte cell line $\mathrm{NMH}^{17}$ was provided by Dr Nelson Fausto (Department of Pathology, University of Washington, Seattle, WA, USA). NMH cells were maintained in DMEM/F-12 medium (Gibco BRL, Gaithersburg, MD, USA), supplemented with $5 \mu \mathrm{g} / \mathrm{ml}$ insulin, $5 \mu \mathrm{g} / \mathrm{ml}$ Tf, $5 \mathrm{ng} / \mathrm{ml}$ selenium (ITS, Sigma, St Louis, MA, USA), $0.04 \mu \mathrm{g} / \mathrm{ml}$ dexamethasone (Sigma), $50 \mu \mathrm{g} / \mathrm{ml}$ gentamycin (Abbott Lab., North Chicago, IL, USA), $120 \mu \mathrm{g} / \mathrm{ml}$ nicotinamide (Sigma) and $20 \mathrm{ng} / \mathrm{ml}$ epidermal growth factor (Collaborative Research, Bedford, MA, USA). After passaging and washing, cells were plated at initial concentrations of $1.0 \times 10^{5} \mathrm{cells} / \mathrm{ml}$ and maintained in the same medium, but without the addition of ITS. On day 2 of culture, human $\mathrm{Tf}$ at concentrations ranging from 0.01 to $25 \mu \mathrm{g} / \mathrm{ml}$ or iron chelator (Fe-SIH) at concentrations ranging from 3.2 to $80 \mu \mathrm{mol}$ were added. After $24 \mathrm{~h}, 500 \mathrm{ng} / \mathrm{ml}$ of aFas was added in the presence of $40 \mu \mathrm{g} / \mathrm{ml}$ of cycloheximide (CHX, Sigma) to induce apoptosis. aFas alone also induced apoptosis in a small portion of NMH cells. The agonistic effect of aFas on $\mathrm{NMH}$ hepatocytes was accentuated in the presence of CHX. ${ }^{19}$ Cells were harvested at $24 \mathrm{~h}$ after the addition of aFas, and the proportion of viable cells was determined by trypan blue dye (Sigma) exclusion. Apoptosis was determined by Annexin V (FITC or PE) staining (Coulter, Corp., Miami, FL, USA) using flow cytometry or by immunocytochemical staining for active caspase-3 expression as described above.

\section{Isolation of mitochondria from NMH cells}

Cell disruption by nitrogen cavitations was used as described $^{20}$ with some modifications. Briefly, NMH cells were harvested, rinsed twice with PBS and cell pellets were frozen at $-70^{\circ} \mathrm{C}$. Cell pellets were then thawed in the mitochondria isolation buffer $11 \mathrm{mM}$ EDTA, $0.25 \mathrm{M}$ sucrose, $10 \mathrm{mM}$ Tris, $\mathrm{pH} 7.4$ and protease inhibitors). Nitrogen cavitation was performed within a pressure vessel at 350-400 psi with 5 min of equilibration time. The resulting suspension was centrifuged twice at $2000 \mathrm{rpm}$ for $5 \mathrm{~min}$, and the spin supernatant was centrifuged at $14000 \mathrm{rpm}$ to recover the mitochondrial pellet. The postmitochondrial supernatant was used as the cytosol fraction. BID expression in mitochondria and cytosol fractions was determined by Western blotting as described above.

\section{Statistics}

Log-rank test (for survival curve) and Student's $t$-test were applied for statistical analysis using GraphPadPrizm (version 3 ) software. Data are presented as mean \pm s.e.

\section{Results}

\section{Tf Protects Against Fas-induced Hepatic Failure}

A dose of aFas of $0.4 \mu \mathrm{g} / \mathrm{g}$ of body weight induced death within 3-6h in all BALB/c mice tested. Over this time course, there was a sharp increase in hepatic transaminase levels (AST; ALT) in plasma (Table 1). BALB/c mice given aFas at doses of $0.07 \mu \mathrm{g} / \mathrm{g}$ of body weight also showed steep increases in blood levels of transaminases and bilirubin (Table 2), but recovered and survived. C57BL6 mice showed a smaller increase in transaminase levels in response to nonlethal doses of aFas than did BALB/c mice consistent with a difference in Fas/Fas-ligand activity in these two mouse strains. ${ }^{21}$ $\mathrm{Tf}$ attenuated transaminase elevations to a greater extent in BALB/c than in C57BL6 mice (Table 2).

$\mathrm{BALB} / \mathrm{c}$ mice given $\mathrm{Tf}$ at doses of $0.5 \mathrm{mg} / \mathrm{mouse}$ i.p. or i.v. two times $(24$ and $0.5 \mathrm{~h}$ before a lethal dose of aFas) survived twice as long as control mice given saline (data not shown). Murine and human Tf 
Table 1 Effect of Tf on Fas-induced hepatic toxicity in mice given lethal doses of aFas

\begin{tabular}{|c|c|c|c|c|}
\hline \multirow{3}{*}{$\begin{array}{l}\text { Hepatic } \\
\text { parameter }\end{array}$} & \multicolumn{4}{|c|}{ Treatment of mice } \\
\hline & \multirow[t]{2}{*}{ None } & \multicolumn{3}{|c|}{ Anti-Fas $m A b(0.4)$} \\
\hline & & +saline & $+T f(0.2)$ & $+T f(1.0)$ \\
\hline ALT (U/l) & $30 \pm 3$ & $6752 \pm 2170$ & $3447 \pm 2586$ & $409 \pm 102^{\mathrm{a}}$ \\
\hline AST (U/l) & $85 \pm 15$ & $8060 \pm 1700$ & $4075 \pm 2524$ & $556 \pm 1266^{b}$ \\
\hline $\begin{array}{l}\text { Active caspase- } \\
3+\text { cells/field }\end{array}$ & $\overline{0}$ & $34 \pm 3$ & $17 \pm 2^{\mathrm{a}}$ & $\mathbf{9} \pm \mathbf{1}^{\mathrm{c}}$ \\
\hline
\end{tabular}

ALT $=$ alanine aminotransferase; AST $=$ aspartate aminotransferase active caspase-3-positive cells were counted as described in Materials and methods; anti-Fas mAb $(0.4)=\mathrm{aFas}$ at a dose of $0.4 \mu \mathrm{g} / \mathrm{g}$ of body weight; Tf $(0.2 ; 1.0)=$ human Tf at a dose of 0.2 or $1.0 \mathrm{mg} / \mathrm{mouse}$ four times (48, 24 and $1 \mathrm{~h}$ before, and $1 \mathrm{~h}$ after aFas administration). Mice were killed $3 \mathrm{~h}$ after the injection of aFas; five mice per group, mean \pm s.e. Bold numbers indicate significant difference as compared to saline + aFas treatment

${ }^{\mathrm{a}} P<0.02$.

${ }^{\mathrm{b}} \mathrm{P}<0.01$.

${ }^{\mathrm{C}} P<0.001$

Table 2 Effect of Tf on blood transaminase levels in mice given nonlethal doses of aFas $(0.07 \mu \mathrm{g} / \mathrm{g}$ of body weight)

\begin{tabular}{|c|c|c|c|}
\hline Mouse strain & Treatment & $A S T(U / I)$ & $A L T(U / I)$ \\
\hline $\mathrm{BALB} / \mathrm{c}$ & $\begin{array}{l}\text { None }(n=4) \\
\text { Saline } \pm \text { aFas }(n=4) \\
\text { Tf+aFas }(n=4)\end{array}$ & $\begin{array}{c}262 \pm 72 \\
5608 \pm 1910 \\
\mathbf{5 1 9}^{ \pm} \mathbf{1 8 6}^{\mathrm{a}}\end{array}$ & $\begin{array}{c}170 \pm 36 \\
3630 \pm 1364 \\
\mathbf{2 7 4}^{ \pm \mathbf{8 6}^{\mathrm{b}}}\end{array}$ \\
\hline C57BL6 & $\begin{array}{l}\text { None }(n=5) \\
\text { Saline+aFas }(n=5) \\
\text { Tf+aFas }(n=6)\end{array}$ & $\begin{array}{c}46 \pm 1 \\
3206 \pm 347 \\
1344 \pm \mathbf{2 3 6}^{\mathrm{b}}\end{array}$ & $\begin{aligned} 23 & \pm 1 \\
1654 & \pm 191 \\
\mathbf{8 7 0} & \pm \mathbf{1 5 0}\end{aligned}$ \\
\hline
\end{tabular}

AST $=$ aspartate aminotransferase; ALT $=$ alanine aminotransferase $\mathrm{Tf}=$ human $\mathrm{Tf}$ at a dose of $0.1 \mathrm{mg} /$ mouse four times $(48,24$ and $1 \mathrm{~h}$ before, and $1 \mathrm{~h}$ after aFas administration). Blood samples were obtained $8 \mathrm{~h}$ after the injection of aFas. $n=$ number of animals; mean \pm s.e. Bold numbers indicate significant difference as compared to saline $+\mathrm{aFas}$ treatment

${ }^{\mathrm{a}} P<0.05$.

${ }^{\mathrm{b}} P<0.02$.

were equally effective, and the effect was independent of the route of $\mathrm{Tf}$ administration. As the doses of murine or human $\mathrm{Tf}$ were further increased to $1 \mathrm{mg} / \mathrm{mouse}$, and were given 48,24 and $1 \mathrm{~h}$ before as well as $1 \mathrm{~h}$ after aFas administration, survival times were progressively prolonged, and $20 \%$ of mice recovered and became long-term survivors (Figure 1a). Similar prolongation of survival $(23.6 \pm 6.9 \mathrm{vs}$ $5.3 \pm 0.3 \mathrm{~h}$ in saline-treated controls; $P<0.02$ ) was also observed in mice given two different preparations of human (rather than murine) Tf (Sclavo or Sigma) (Figure 1b). With increasing doses of Tf, blood plasma transaminase levels decreased towards normal, and the number of active caspase-3expressing cells in the liver was reduced (Table 1).

It was of note that mice pretreated with one of two HSA preparations (Sigma), intended to serve as controls, also experienced some prolongation of survival $(18.0 \pm 7.2 \mathrm{~h})$ (Figure 1b). Western blot
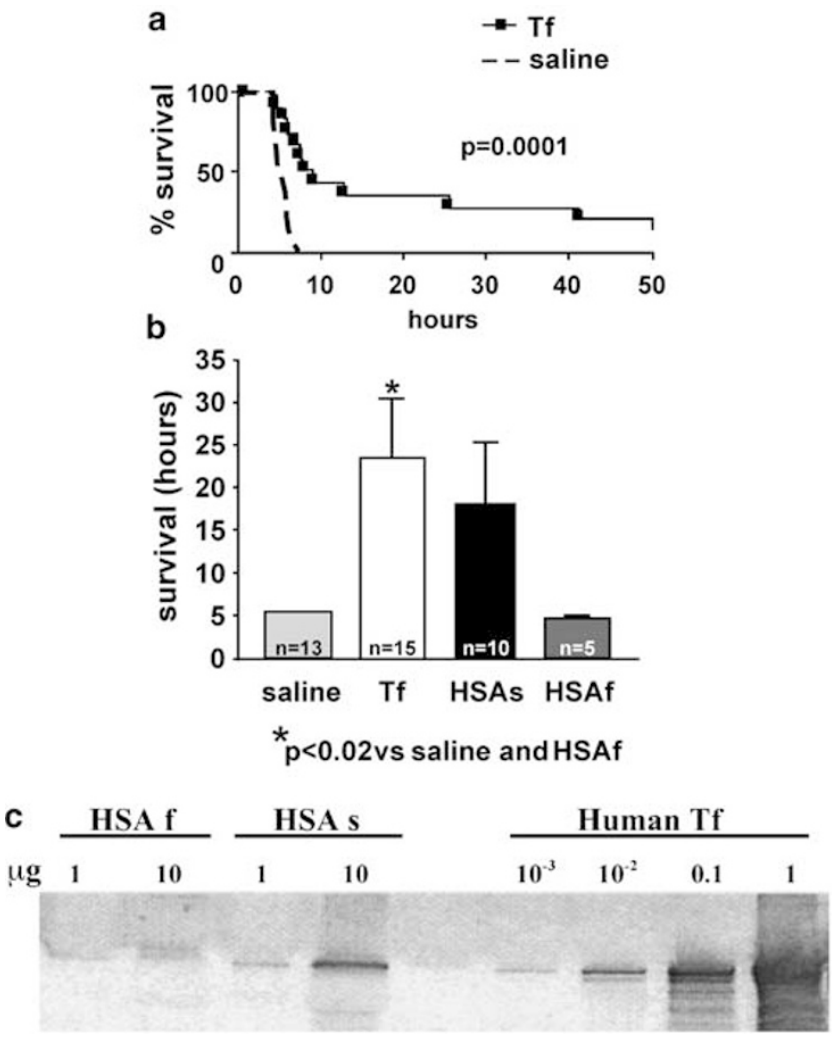

Figure 1 Effect of human Tf or HSA on the survival of mice after injection of anti-Fas mAb (aFas). Female 3- to 5-month-old BALB/ c mice were given aFas i.p. at doses of $0.4 \mu \mathrm{g} / \mathrm{g}$ of body weight in a volume of $0.25 \mathrm{ml}$, and survival times were recorded. (a) Effect of human Tf on survival. In addition to aFas injection, mice were given either $0.25 \mathrm{ml}$ saline ( $n=13)$, or human Tf (Sclavo or Sigma) injected i.p. at a dose of $1.0 \mathrm{mg} / \mathrm{mouse}$ in a volume of $0.25 \mathrm{ml}$ at $48,24,1 \mathrm{~h}$ before and $1 \mathrm{~h}$ after aFas administration $(n=15)$ $(P=0.0001$; log-rank test). (b) Effect of human Tf or HSA preparations on survival. In addition to aFas injection, mice were given either $0.25 \mathrm{ml}$ saline $(n=13)$ or human Tf $(n=15)$, or HSA from Sigma (HSAs $(n=10)$ ) or HSA from Fluka (HSAf $(n=5)$ ) at doses of $1 \mathrm{mg} / \mathrm{mouse}$ in a volume of $0.25 \mathrm{ml}$ at 48,24 and $1 \mathrm{~h}$ before and $1 \mathrm{~h}$ after aFas administration. There was a significant prolongation of survival not only with $\mathrm{Tf}$ but also with the albumin preparation HSAs. (c) Quantitative anti-Tf Western blot with HSA preparations and plasma Tf as standard. HSA from Fluka (HSAf), HSA from Sigma (HSAs) and human Tf were analyzed by Western immunoblot for Tf. Results show that HSAs contained between 0.1 and $0.2 \%$ Tf $(0.01-0.02 \mu \mathrm{g}$ Tf per $10 \mu \mathrm{g}$ total protein), consistent with the observed protective effect. Tf contamination in HSAf was between 0.001 and $0.01 \%$.

analysis of the HSA preparations revealed contamination with Tf (Figure 1c), and the extent of survival prolongation correlated with Tf contamination (Figure 1b). Injections of LPS (0.1-3.0 ng/ mouse, in $0.25 \mathrm{ml}$ i.p. $\times 4$ times) as endotoxin control did not affect survival (data not shown).

Livers of mice receiving lethal doses of aFas and no Tf contained numerous periportal hepatocytes displaying apoptosis with rounding up and condensation of cytoplasm, and nuclear fragmentation. The sinusoids are congested to frankly hemorrhagic with loss of the hepatocyte cord architecture. In contrast, the liver architecture was intact and 

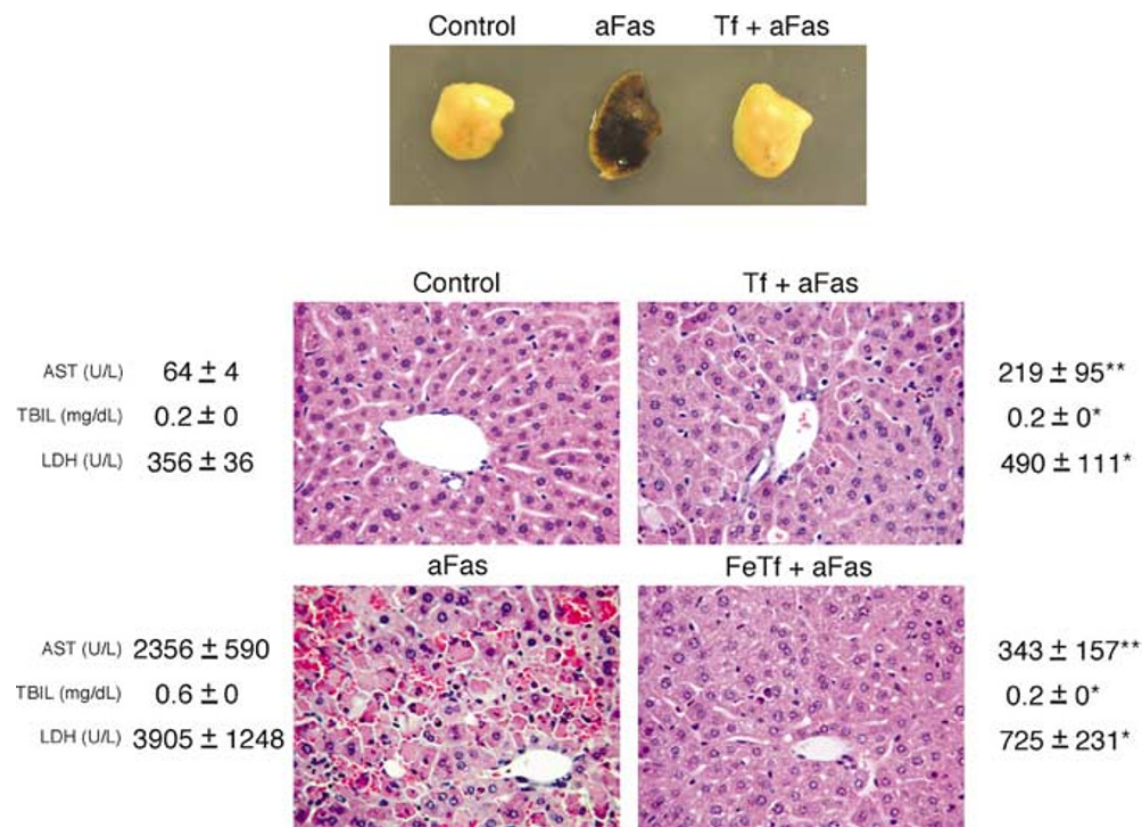

Figure 2 Hepatic injury induced by lethal doses of aFas. BALB/c mice (four to eight animals/group) were given aFas (0.4 $\mu \mathrm{g} / \mathrm{g}$ of body weight) and either saline or human Apo-Tf or iron-saturated Tf (Fe-Tf) at doses of $1 \mathrm{mg} / \mathrm{mouse}$ at 48,24 and $1 \mathrm{~h}$ before, and $1 \mathrm{~h}$ after aFas. Mice were bled (for blood plasma samples) and killed $3 \mathrm{~h}$ after aFas injection. Liver tissue was harvested after total body perfusion with saline. (a) Macroscopic appearance of right liver lobe from a mouse given saline (control), a mouse injected with aFas and saline (aFas) and a mouse injected with aFas and $\mathrm{Tf}(\mathrm{Tf}+\mathrm{aFas})$. (b) Formalin-fixed, paraffin-embedded organ sections were stained with hematoxylin/ eosin ( $\times 128)$. Livers from aFas-treated mice showed marked apoptosis and sinusoidal hemorrhage, which were considerably reduced (apoptosis) or absent (hemorrhage) in $\mathrm{Tf}$ pre-treated mice ( $\mathrm{Tf}+\mathrm{aFas}$ ) and in Fe-Tf pre-treated mice (Fe-Tf $+\mathrm{aFas})$. AST, total bilirubin (TBIL) and LDH plasma levels of Tf-treated mice decreased towards normal. The means \pm s.e. are shown, ${ }^{*} P<0.05$, ${ }^{* *} P<0.02$.

without hemorrhage, and only rare apoptotic hepatocytes were present in mice pretreated with Tf either in its Apo- or iron-saturated form (Figure 2). Plasma AST, LDH and bilirubin levels of Tf-treated mice decreased towards normal (Figure 2). Apo-Tf and iron saturated $\mathrm{Tf}$ (Fe-Tf) were equally effective.

\section{Tf Reduces Cleavage of BID and Cytochrome c Release, Blocks Caspase-9 and -3 activation and Upregulates Expression of Bcl-xL}

Livers of mice treated with aFas and no $\mathrm{Tf}$ showed hepatocyte apoptosis as determined by both immunohistochemical staining for active caspase-3 (Figure 3a) and TUNEL technique (Figure 3b). The extent of apoptosis was significantly diminished in animals pretreated with Tf (Figure 3, Table 1). At this time point ( $3 \mathrm{~h}$ after aFas injection), Western blots of liver tissue lysates from mice given aFas showed decreased levels of full-length caspase-8 and -10 . Earlier time points ( 0.5 and $1.5 \mathrm{~h}$ after aFas) showed no significant changes in the expression of these two 'initiator' caspases nor of 'executioner' caspase-3 (Figures 4 and 6). Western blots of liver tissue lysates from aFas-treated mice showed decreased levels of full-length BID as well as decreased levels of caspase- 9 with the appearance of a typical caspase-9 cleavage product (Figures 5a and 6). Control mice treated with Apo-Tf or Fe-Tf showed a

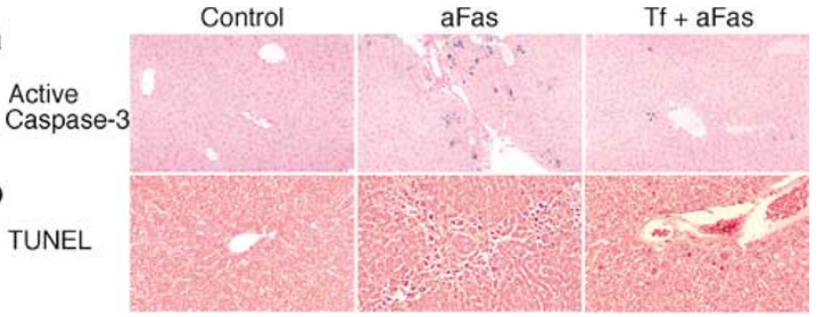

Figure 3 Liver sections of mice treated with aFas with or without pretreatment with human Tf. (a) BALB/c mice were given saline (control), lethal doses of aFas ( $0.4 \mu \mathrm{g} / \mathrm{g}$ of body weight) plus either saline (aFas) or human Apo-transferrin ( $\mathrm{Tf}+\mathrm{aFas}$ ) at doses of $1 \mathrm{mg} /$ mouse at 48,24 and $1 \mathrm{~h}$ before, and $1 \mathrm{~h}$ after aFas. Mice were killed $3 \mathrm{~h}$ after aFas injection. Formalin-fixed, paraffin-embedded organ sections were stained immunohistochemically for active caspase-3 $(\times 80)$. There was prominent staining in aFas-treated mice and a markedly lower frequency in mice pretreated with $\mathrm{Tf}$. (b) BALB/c mice were given saline (control), nonlethal doses of aFas $(0.07 \mu \mathrm{g} / \mathrm{g}$ of body weight) plus either saline (aFas) or human Apo-transferrin $(\mathrm{Tf}+\mathrm{aFas})$ at doses of $0.1 \mathrm{mg} / \mathrm{mouse}$ at 48,24 and $1 \mathrm{~h}$ before, and $1 \mathrm{~h}$ after aFas. Mice were killed $8 \mathrm{~h}$ after the injection of aFas. Apoptotic cells were determined in formalinfixed, paraffin-embedded liver sections by TUNEL assay $(\times 80)$. The pattern was similar to that with active caspase- 3 staining, showing multiple apoptotic cells in aFas-treated animals and a few in mice pretreated with Tf.

a slight increase in the amount of full-length BID relative to saline-treated animals without significant changes in caspase-9. Mice given Apo-Tf or Fe-Tf in addition to aFas showed higher levels of BID and intact caspase-9 than did mice treated with aFas 
Liver cell lysate

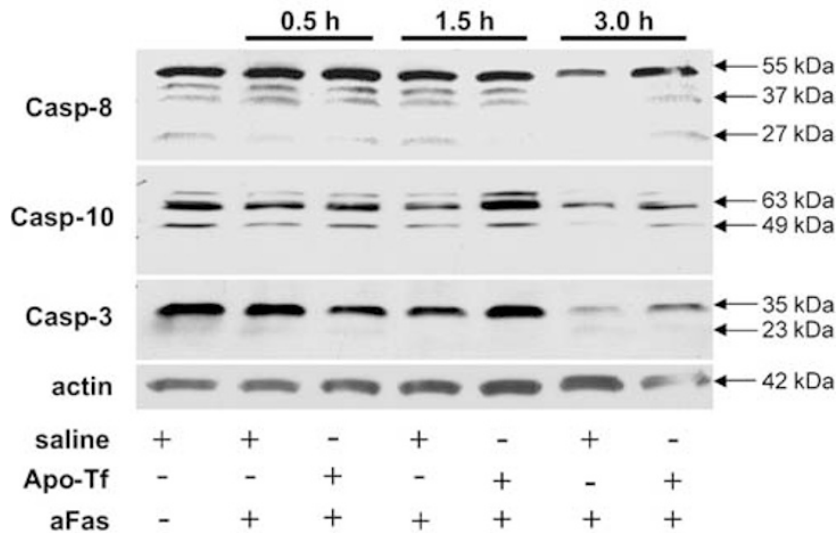

Figure 4 Caspase-8, -10 and -3 expressions in the liver at different times after aFas injection. BALB/c mice were given aFas and treated with Apo-Tf as described in Figure 2. Mice were killed at $0.5,1.5$ and $3 \mathrm{~h}$ after aFas injection. After total body perfusion with saline, liver tissue was collected, frozen and lysed in Chaps buffer. The cell extracts were analyzed by SDS-PAGE and immunodetected with anti-mouse caspase-8, -10 and -3 antibody, respectively. Western blots from one of two similar experiments are shown. There were no significant changes in the expression of full-length caspases under study at 0.5 and $1.5 \mathrm{~h}$ after aFas administration; at $3.0 \mathrm{~h}$, the expression of all caspases was reduced in mice given aFas, and the reduction was decreased in mice pretreated with $\mathrm{Tf}$.

only, although levels of caspase-9 remained below those seen in mice not given aFas and treated with Apo-Tf or Fe-Tf only (Figure 5a).

The observed changes in BID and caspase-9 were consistent with the pattern of cytochrome $c$ release. Cytochrome $c$ was not detected in the blood plasma of control mice. In contrast, there was an increase of cytochrome $c$ in the blood plasma of aFas-treated animals. Mice treated with Apo-Tf or Fe-Tf in addition to aFas showed only minute amounts (with Apo-Tf) or no cytochrome $c$ at all (with $\mathrm{Fe}$-Tf) in blood plasma (Figure 5b).

In line with immunohistochemical observations (Figure 3a), there was a significant reduction in fulllength caspase-3 levels in aFas-treated animals, suggesting cleavage of this 'executioner' caspase. Mice given Apo-Tf or Fe-Tf in addition to aFas showed levels of full-length (noncleaved) caspase-3 considerably higher than that in mice given aFas and saline only (Figures 4, 5a and 6).

Levels of Bcl-xL were decreased in aFas-treated mice compared to saline-injected controls. The administration of Fe-Tf (but not Apo-Tf) by itself resulted in an increase in Bcl-xL protein expression. There was a striking further increase in Bcl-xL protein levels in mice injected with Apo-Tf or Fe-Tf in addition to aFas (Figures 5a and 6).

These findings suggest that the administration of Tf resulted in a resetting of the balance between proand antiapoptotic members of the Bcl-2 family that was altered by Fas-triggered signals. a

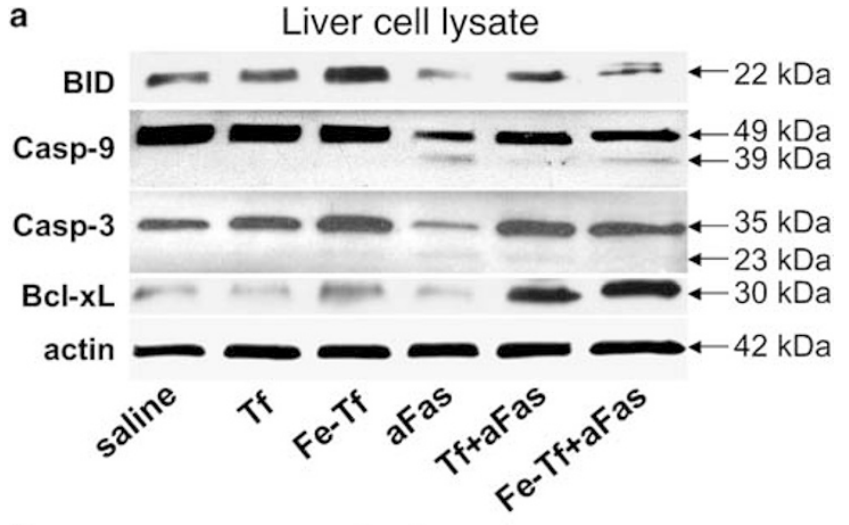

b

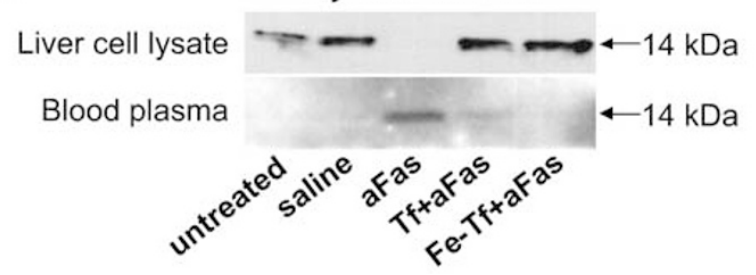

Figure 5 Tf reduces BID, caspase-9 and -3 cleavage, cytochrome $C$ release, and increases Bcl-xL expression in the liver. BALB/c mice were given aFas and treated with Apo-Tf or Fe-Tf as described in Figure 2. Mice were killed $3 \mathrm{~h}$ after aFas injection. After total body perfusion with saline, liver tissue was collected, frozen and lysed in Chaps buffer. The cell extracts were analyzed by SDS-PAGE and immunodetected with anti-mouse BID, caspase-9, caspase-3, cytochrome $c$ and Bcl-xL antibody, respectively. Blood plasma was treated identically for cytochrome $c$ determination. Western immunoblots of one from four similar experiments are shown. (a) There was a decrease in levels of full-length BID, caspase-9, caspase- 3 and Bcl-xL (with the appearance of caspase- 9 and -3 cleavage products) in the liver in response to aFas; the decrease was reduced after pretreatment with Tfs. (b) An increase of cytochrome $c$ in blood plasma of mice receiving aFas was prevented or reduced by Tfs.

\section{What is the role of Iron in the antiapoptotic effect of Tf?}

In an attempt to define a possible role of iron in the effects of Tf observed in vivo, experiments were carried out on murine hepatocytes in vitro. Tf protected NMH hepatocytes against Fas-mediated cell death (Figure 7a). aFas increased the proportion of Annexin V-positive NMH cells from a baseline of $5 \%$ (range $2-8 \%$ ) to $15 \%$ (range $8-22 \%$ ). The concurrent presence of $\mathrm{Tf}$ reduced the proportion of apoptotic cells by $20-50 \%$ (Figure 7b). Similarly, Tf decreased the activation of caspase-3 (Figure 8). Among NMH cells treated with aFas, $28 \pm 2 \%$ stained for active caspase- 3 at $12 \mathrm{~h}$, and $33 \pm 3 \%$ at $24 \mathrm{~h}$ after the addition of aFas. In the presence of Tf, these proportions were reduced to $18 \pm 2 \%(P<0.02)$ and $16 \% \pm(P<0.01)$, respectively.

It is of note that Fe-Tf and iron-free Apo-Tf provided protection, although Fe-Tf was less effective (Figure 9). Comparing the means of the average values of $\mathrm{Fe}$-Tf vs Apo-Tf showed a statistically significant difference $(5.8 \pm 0.2$ vs $4.4 \pm 0.4 \%$, 


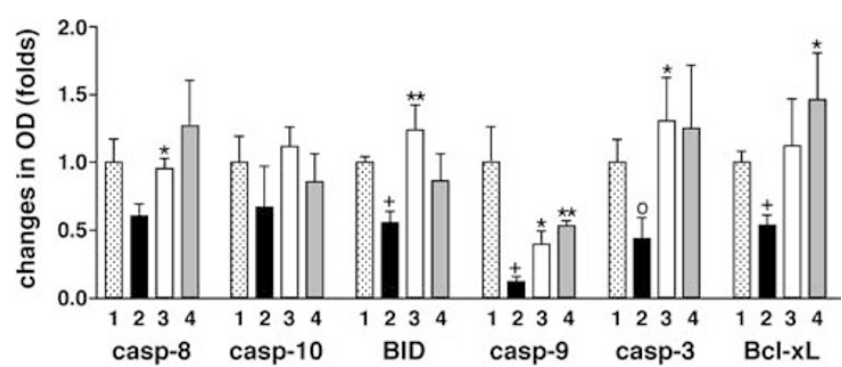

Figure 6 Levels of expression of caspase-8, -10, -9 and -3 and BID and Bcl-xL in mouse liver in vivo. BALB/c mice were given aFas and treated with Apo-Tf or Fe-Tf as described in Figure 2. Mice were killed $3 \mathrm{~h}$ after aFas injection. After total body perfusion with saline, liver tissue was collected, frozen and lysed in Chaps buffer. The cell extracts were analyzed by SDS-PAGE and immunodetected with anti-mouse caspase-8 (casp-8), caspase-10 (casp-10), full-length BID (BID), caspase-9 (casp-9), caspase-3 (casp-3) and Bcl-xL antibody, respectively. For each factor, optical density (OD) of the protein signal (determined with $1.62 \mathrm{NIH}$ image) in liver cell lysates from mice receiving saline only served as a reference (1.0). The means \pm s.e. of four experiments are shown. Levels of all four caspases, BID and Bcl-xL decreased following aFas exposure; the decrease was prevented or reduced after pretreatment with Tfs. Treatment: $1=$ saline; $2=$ saline + aFas; $3=$ Apo-Tf + aFas; $4=$ Fe-Tf + aFas; ${ }^{\circ} P<0.05$; ${ }^{+} P<0.02$ vs 'saline'; ${ }^{*} P<0.05,{ }^{*} P<0.01$ vs 'saline + aFas'.
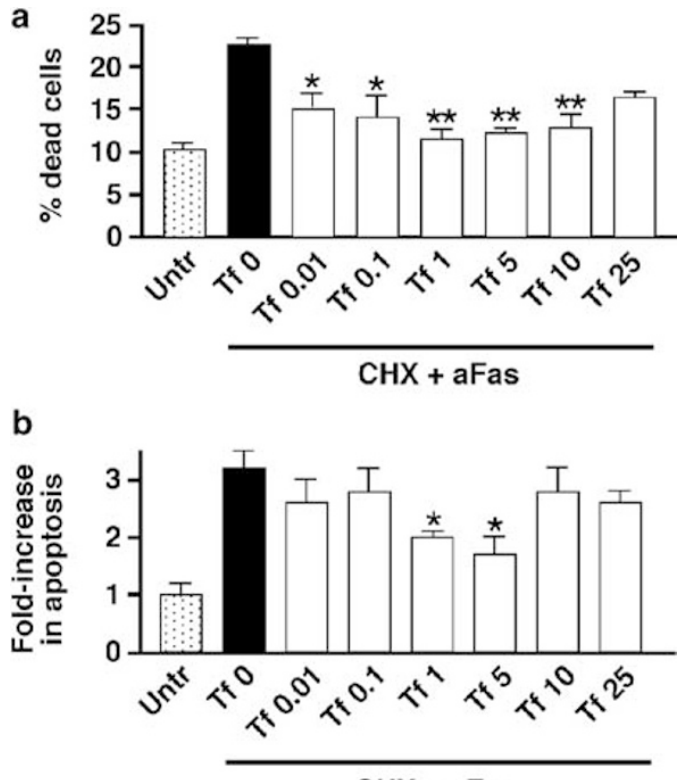

$\mathrm{CHX}+\mathrm{aFas}$

Figure $7 \mathrm{Tf}$ protects NMH cells against apoptosis induced by aFas. Cells were cultured in triplicate and treated with $\mathrm{Tf}(0.01-$ $25 \mu \mathrm{g} / \mathrm{ml}$ on day 2 of culture). aFas at a concentration of $500 \mathrm{ng} / \mathrm{ml}$ was added $24 \mathrm{~h}$ after $\mathrm{Tf}$ (and $30 \mathrm{~min}$ after $40 \mu \mathrm{g} / \mathrm{ml}$ of cycloheximide (CHX)). Each bar shows the mean \pm s.e. of four to 20 experiments, ${ }^{*} P<0.01,{ }^{*} P<0.001$; untr $=$ untreated. (a) Cell viability was assessed by trypan blue exclusion $24 \mathrm{~h}$ after aFas. The proportion of dead cells decreased with Tf pretreatment. There was some evidence for a biphasic response to Tf. (b) Apoptotic cells were identified by flow cytometry using Annexin V-staining. The proportion of Annexin V-positive cells in untreated samples served as a reference point. There was a significant reduction in Annexin V-positive cells at Tf concentrations of 1 and $5 \mu \mathrm{g} / \mathrm{ml}$. As in (a) there was evidence of a biphasic response.

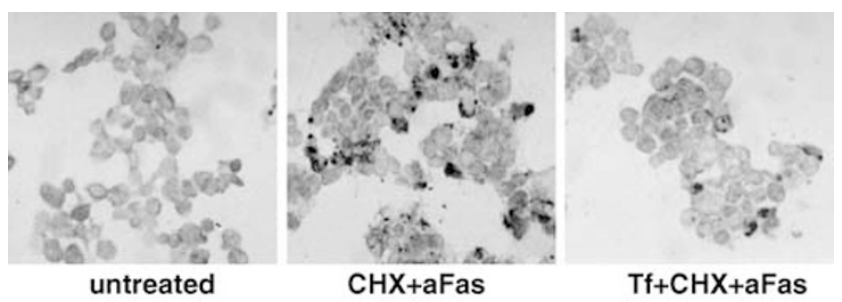

Figure $8 \mathrm{Tf}$ pretreatment reduces the proportion of active caspase-3-expressing NMH cells after exposure to aFas. Tf (5 $\mu \mathrm{g} /$ $\mathrm{ml}$ ) was added to cultures $24 \mathrm{~h}$ prior to CHX $+\mathrm{aFas}$. After $12 \mathrm{~h}$, cells were harvested, placed on adhesive slides, fixed with acetone and analyzed immunohistochemically for active caspase3 expression (black staining). Results of one of four similar experiments are shown.
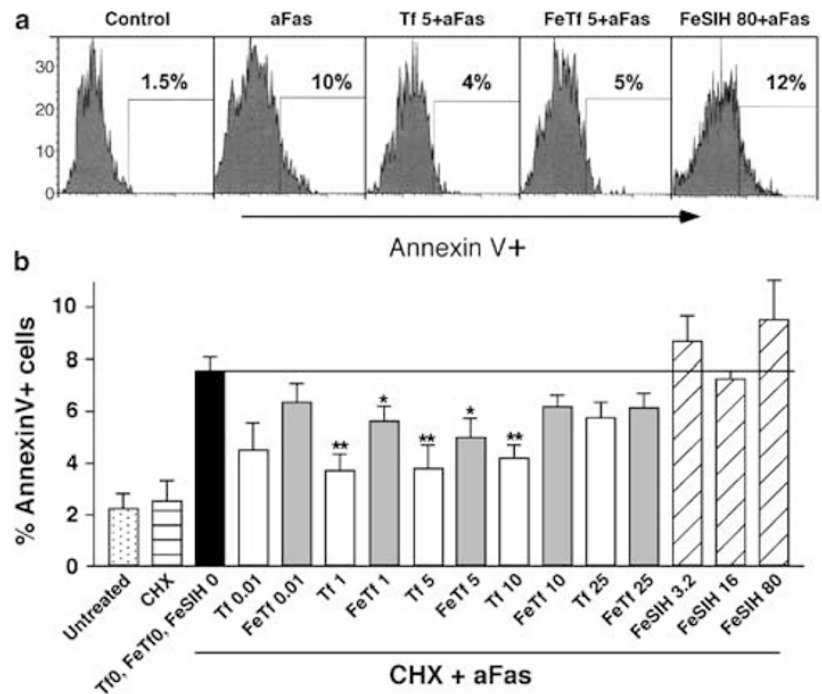

Figure 9 Apo-Tf (Tf) and iron saturated Tf (Fe-Tf) but not FeSIH provide cytoprotection against Fas-induced apoptosis in $\mathrm{NMH}$ hepatocytes. Cells were cultured in triplicate and treated with human Tf, Fe-Tf $(0.01-25 \mu \mathrm{g} / \mathrm{ml})$ or with iron-saturated salicylaldehyde isonicotinoyl hydrazone (FeSIH, $3.2-80 \mu \mathrm{mol} / \mathrm{ml}$ ) on day 2 of culture. aFas at $500 \mathrm{ng} / \mathrm{ml}$ was added $24 \mathrm{~h}$ after Tf, Fe-TF or FeSIH (and $30 \mathrm{~min}$ after $40 \mu \mathrm{g} / \mathrm{ml}$ cycloheximide (CHX)). Cells were harvested $24 \mathrm{~h}$ after the addition of aFas, and apoptotic cells were determined by flow cytometry using Annexin V staining (a); results of one of three similar experiments are schematically summarized in (b). The means \pm s.e. of triplicate cultures are shown; ${ }^{*} P<0.05,{ }^{*} P<0.02$ vs $\mathrm{CHX}+\mathrm{aFas}$. There was a protective effect of Tf against apoptosis, more so with Apo-Tf than with Fe-Tf. FeSIH showed no protective effect, and results suggest, in fact, an enhancement of apoptosis.

respectively, $P<0.02, n=5$, Student's $t$-test). The iron-chelator SIH is capable of iron delivery when saturated with $\mathrm{Fe}(\mathrm{Fe}-\mathrm{SIH}){ }^{15}$ bypassing the physiological Tf-receptor (CD-71) pathway. Iron from FeSIH is used efficiently by cells to support proliferation. ${ }^{2}$ As shown in Figure 9, Fe-SIH failed to provide an antiapoptotic effect in hepatocytes, consistent with the notion that the observed antiapoptotic properties of $\mathrm{Tf}$ were dependent upon the carrier molecule and were not mediated by $\mathrm{Fe}$ alone. Furthermore, NMH cells were treated with Tf and aFas in the presence or absence of the anti-CD71 42/6, which completely prevents iron uptake via CD71 


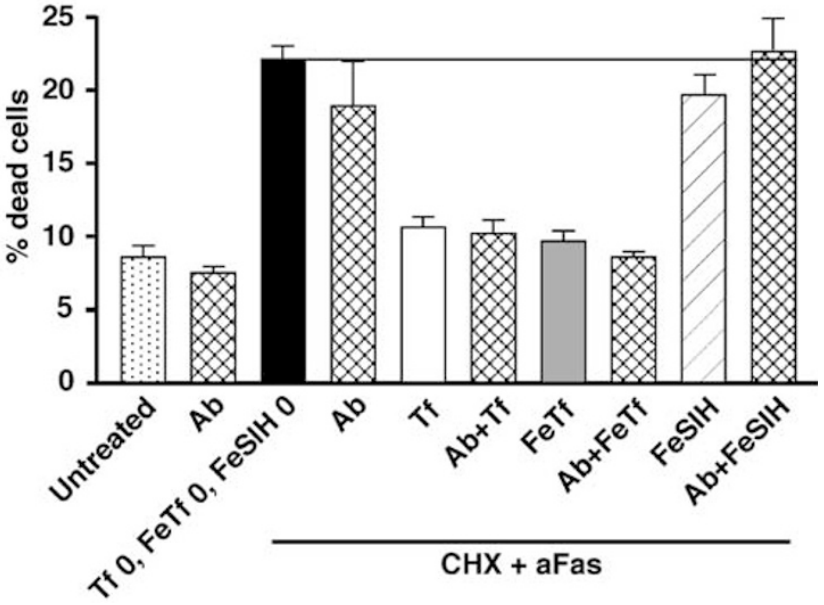

Figure 10 Anti-CD71 MAB does not block the effects of Apo- or Fe-Tf on Fas-induced cell death in NMH hepatocytes. Hepatocytes were cultured in triplicate and treated with human Apo- or Fe-Tf $(5 \mu \mathrm{g} / \mathrm{ml})$ or with iron-saturated salicylaldehyde isonicotinoyl hydrazone $(\mathrm{FeSIH}, 80 \mu \mathrm{mol} / \mathrm{ml})$ added on day 2 of culture. Anti-CD71 MAB (Ab) $(42 / 6,12 \mu \mathrm{g} / \mathrm{ml})$ was added $15 \mathrm{~min}$ before Tf, FeTf or FeSIH. aFas (500 ng/ml) was added $24 \mathrm{~h}$ after Tf, FeTf or FeSIH (and $30 \mathrm{~min}$ after $40 \mu \mathrm{g} / \mathrm{ml}$ of cycloheximide (CHX)). Cells were harvested $24 \mathrm{~h}$ after the addition of aFas, and dead cells were enumerated using Trypan blue dye exclusion. The means \pm s.e. of three experiments are shown. The protective effect of Tf persisted in the presence of anti-CD71 MAB.

(Trowbridge and Lopez). ${ }^{39}$ As shown in Figure 10, the presence of MAB 42/6 did not interfere with the ability of Tf to protect NMH hepatocytes against Fasinitiated signals. These findings also argue against a role of CD71 in the antiapoptotic effect of Tf.

\section{Modulation of Fas-induced BID Protein Expression by Tf in Murine NMH Hepatocytes}

We induced apoptosis in NMH cells by aFas in the absence of CHX (an inhibitor of protein synthesis) to avoid its possible interference with the expression of proteins under study. In whole-cell lysates, Tf inhibited Fas-induced increases in full-length (p22) BID protein expression (Figure 11a) in a dosedependent manner. As shown in Figure 11b, strong expression of p22 BID in the cytosol of NMH cells was observed at 1, 6, 12 and $24 \mathrm{~h}$ after Fas ligation. Tf alone did not significantly modify BID expression, but had a profound effect on Fas-induced changes in p22 BID protein, more striking in mitochondria than in the cytosol fraction. These changes were markedly time dependent. In addition to p22 BID, cleavage products of BID (truncated BID [tBID, p15]) were detectable in mitochondria in minute amounts, decreasing with increasing $\mathrm{Tf}$ concentrations at the 12-h time point (Figure 11c).

\section{Discussion}

These studies show a profound protective effect of Tf against Fas-triggered liver cell death similar to a

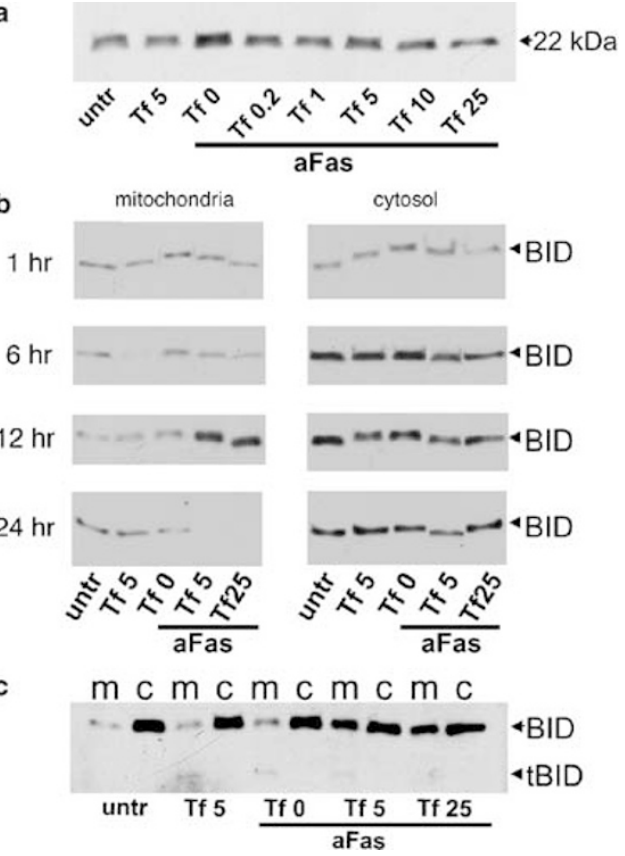

Figure 11 Modulation of Fas-induced BID protein expression by $\mathrm{Tf}$ in whole-cell lysates (a) and in mitochondria (m) and cytosol (c) fractions (b and $\mathbf{c}$ ). On day 2 of NMH cell culture, human Tf was added at concentrations of $0.2-25 \mu \mathrm{g} / \mathrm{ml}$ as indicated. After $24 \mathrm{~h}, 250 \mathrm{ng} / \mathrm{ml}$ of aFas was added. Cells were harvested at different time points and lysed in RIPA buffer, or mitochondrial fractions were isolated by using a nitrogen cavitation method. The cell extracts were analyzed by SDS-PAGE and immunodetected with anti-mouse BID antibody. Western blots of one from three (a) and one from two (b and c) similar experiments are shown. Tf counteracted Fas-induced increase in BID [p22] expression in whole-cell lysates, and modulated BID [p22] and tBID [p15] expression in mitochondria fraction in a time-dependent manner. Levels of full-length BID in mitochondria increased at $12 \mathrm{~h}$ when minute amounts of tBID [p15] were also detectable.

that previously demonstrated for lymphohemopoietic cells. ${ }^{6}$ The observed cytoprotective effects of Tf did not appear to be iron dependent and were not achievable with iron alone.

Hepatocytes prominently express the death receptor Fas, and Fas-mediated signals can induce severe hepatocyte injury, presumably via apop tosis. ${ }^{7,11}$ Fas ligation activates 'initiator' caspases-8 and -10, which in hepatocytes affect a mitochondrial pathway to maximize Fas-induced apoptosis. ${ }^{22}$ Others have shown that BID protein is required for hepatocyte apoptosis and liver failure induced by aFas. ${ }^{23,24}$ BID is generally cleaved in response to Fas, TNF $\alpha$ or TRAIL signaling and thereby converted to its truncated, active form tBID, ${ }^{25,26}$ which induces cytochrome $C$ release and downstream caspase activation. Our results show that Tf modified BID responses to Fas signaling. The fact that we observed predominantly full-length p22 BID (as well as uncleaved caspase-8, -10 and -3) rather than an increase in tBID (or cleaved forms of caspase-8, -10, and -3 ) in response to death signals was unexpected. The possible reasons for this might be as follows: (1) very low concentrations of the active forms, a fast 
metabolism and low protein stability; (2) the peculiarities of liver tissue damage in response to agonistic anti-Fas MAB: high local proteolytic activity associated with alterations in blood supply, oxidative stress and release of active proteases. In mice, moderate doses of aFas induce neutrophil recruitment, which potentiate liver injury by release of oxidants and proteases; ${ }^{27}$ (3) the dose of Jo2 MAB ( $0.4 \mu \mathrm{g} / \mathrm{g}$ of body weight) was sufficient to kill mice but insufficient to induce extensive protein cleavage to produce sufficient amounts of active proteins to be detectable by the methods used. However, it has been shown in HepG2 cells that even subnanomolar doses of exogenous tBID induce rapid cytochrome $c$ release from mitochondria, ${ }^{28}$ and translocation of p22 BID, considered the inactive form of BID, has been described in other models. ${ }^{28,29}$ In Jurkat cells, Fas-mediated apoptosis involves the translocation of full-length p22 BID to the mitochondria, inducing cytochrome $C$ release and cell death in the absence of BID cleavage. ${ }^{30}$ Our in vitro data showed that $\mathrm{Tf}$ by itself did not significantly modify p22 BID expression in NMH hepatocytes. However, Tf interfered with the action of Fas-mediated signals on the p22 and p15 forms of BID proteins, possibly affecting translocation, cleavage or both (Figure 11). The observed interference of $\mathrm{Tf}$ with the expression of BID and Fas-induced activation of caspase- 3 is consistent with observations by Yin et $a l,{ }^{23}$ who showed that BID-deficient mice were highly resistant to Fas-initiated hepatic damage. In the present model, BID was available, but its function was compromised in the presence of Tf. As a consequence, cytochrome $c$ release decreased and caspase-9 cleavage was prevented or reduced. The result was a lack of 'effector' caspase-3 activation and a reduction in apoptosis.

One potential mechanism by which Tf could interfere with the action of BID on cytochrome $c$ release is the modulation of intracellular concentrations of $\mathrm{Mg}^{2+} . \mathrm{Mg}^{2+}$ mobilization is an early event in Fas-mediated apoptosis in $\mathrm{B}$ cells $^{31}$ and in glycodeoxycholate-induced apoptosis in rat hepatocytes. ${ }^{32}$ An increase in free cytosolic $\mathrm{Mg}^{2+}$ facilitates the BID- or Bax-mediated release of cytochrome $C$ from the mitochondria. ${ }^{31,33}$ Thus, binding of $\mathrm{Mg}^{2+}$ by Tf may contribute to the antiapoptotic effects of Tf.

In addition to interfering with proapoptotic signals, Tf also enhanced survival signals. The expression of Bcl-xL was increased by Tf (Figures 4 and 5a). Tf was previously shown to induce Bcl$2,{ }^{34}$ and Bcl-2 and Bcl-xL are known to be released following phosphorylation of BAD. ${ }^{35}$ One pathway leading to BAD phosphorylation is via insulin-like growth factor (IGF)-mediated activation of PI3kinase and $\mathrm{Akt}^{36}$ Weinzimer et $a l^{5}$ and Storch et $a l^{37}$ recently showed that $\mathrm{Tf}$ is a natural ligand for the IGF binding protein 3 (IGFBP-3) and also binds IGFs. In cell cultures, IGFBP-3 regulates apoptosis in human breast and prostate cancer (PC-3) cells,, and the addition of Tf to cultures of PC-3 cells prevented apoptosis induced by IGFBP-3. ${ }^{5}$ Preliminary studies in our laboratory show a similar interaction of Tf with IGFBP-3 in normal lymphohemopoietic cells and hepatocytes (unpublished observations).

Iron is essential for cellular functions ${ }^{2}$ and it would be conceivable that iron plays a role in the cytoprotective effects of Tf. Previous studies indicated that the antiapoptotic effect of $\mathrm{Tf}$ was iron independent. ${ }^{6}$ The current results with apo-Tf, Fe-Tf and the iron-chelator SIH support this hypothesis. Furthermore, as noted already, the presence of an anti-CD71 mAb that blocks iron uptake ${ }^{39}$ did not interfere with the antiapoptotic effects of $\mathrm{Tf}$ in marrow cells ${ }^{6}$ nor in NMH hepatocytes (Figure 10). The present observations also offer at least one answer as to why the observed Tf action was not blocked by anti-CD71 mAb. If Tf can function via an IGF/IGFBP3 pathway, the classic Tf receptor would not be required.

The fact that murine and human $\mathrm{Tf}$ exerted comparable protective effects on murine hepatocytes may not be surprising, as mouse Tf has $83 \%$ homology with human $\mathrm{Tf}^{40}{ }^{40}$ and both Tfs have very similar physicochemical characteristics. ${ }^{41}$

Thus, exogenous Tf conveyed potent antiapototic/ cytoprotective effects against Fas-mediated signals in hepatocytes, and data presented elsewhere indicate that the protective effects of $\mathrm{Tf}$ are not restricted to Fas-induced death signals. ${ }^{6,42}$ The mechanism involves interference of $\mathrm{Tf}$ with the signal cascade of apoptosis, specifically BID expression, cytochrome $c$ release, caspase- 3 and caspase- 9 activation and Bcl-xL expression. These data suggest that Tf may be useful as a hepatoprotective agent.

\section{Acknowledgement}

We thank Dr S Arrighi for transferrin preparation; Dr N Fausto for his suggestions and for providing murine hepatocyte cell line NMH; Dr P Ponka for providing iron chelator (SIH); Dr IS Trowbridge for providing anti-CD71 MAB 42/6; Jessica Ward for generous help with Western analysis; and B Larson and $\mathrm{H}$ Crawford for their help with the manuscript.

This work was supported by Grant HL36444 from the National Institutes of Health, DHHS, Bethesda, MD, USA and grants from the Interbion Foundation, Switzerland, Cellena AG, Switzerland and Fujisawa Healthcare Inc., USA.

\section{References}

1 de Jong G, van Dijk JP, van Eijk HG. The biology of transferrin [Review]. Clin Chim Acta 1990;190:1-46.

2 Ponka P, Beaumont C, Richardson DR. Function and regulation of transferrin and ferritin [Review]. Semin Hematol 1998;35:35-54. 
3 Pierpaoli W, Lesnikov VA, Lesnikova MP, et al. Unresponsiveness to human leukocytes in immunosuppressed mice by combined donor-derived human transferrin and antigens. Transplant Immunol 1996;4:301-308.

4 Deeg HJ, Pierpaoli W, Arrighi S, et al. Facilitation of DLA-incompatible marrow grafts by donor-specific serum transferrin? Transplant Immunol 1996;4: 113-116.

5 Weinzimer SA, Gibson TB, Collett-Solberg PF, et al. Transferrin is an insulin-like growth factor-binding protein-3 binding protein. J Clin Endocrinol Metab 2001;86:1806-1813.

6 Lesnikov V, Lesnikova M, Deeg HJ. Pro-apoptotic and anti-apoptotic effects of transferrin and transferrinderived glycans on hematopoietic cells and lymphocytes. Exp Hematol 2001;29:477-489.

7 Ogasawara J, Watanabe-Fukunaga R, Adachi M, et al. Lethal effect of the anti-Fas antibody in mice [published erratum appears in Nature 1993 Oct 7;365(6446):568]. Nature 1993;364:806-809.

8 Galle PR, Hofmann WJ, Walczak H, et al. Involvement of the CD95 (APO-1/Fas) receptor and ligand in liver damage. J Exp Med 1995;182:1223-1230.

9 Griffith TS, Brunner T, Fletcher SM, et al. Fas ligandinduced apoptosis as a mechanism of immune privilege. Science 1995;270:1189-1192.

10 French LE, Wilson A, Hahne $\mathrm{M}$, et al. Fas ligand expression is restricted to nonlymphoid thymic components in situ. J Immunol 1997;159:2196-2202.

11 Nishimura Y, Hirabayashi Y, Matsuzaki Y, et al. In vivo analysis of Fas antigen-mediated apoptosis: effects of agonistic anti-mouse Fas mAb on thymus, spleen and liver. Int Immunol 1997;9:307-316.

12 Liem LM, van Lopik T, van Nieuwenhuijze AE, et al. Soluble Fas levels in sera of bone marrow transplantation recipients are increased during acute graft-versushost disease but not during infections. Blood 1998;91:1464-1468.

13 Gores GJ, Kaufmann SH. Is TRAIL hepatotoxic? [Review]. Hepatology 2001;34:3-6.

14 Janin A, Deschaumes C, Daneshpouy M, et al. CD95 engagement induces disseminated endothelial cell apoptosis in vivo: immunopathologic implications. Blood 2002;99:2940-2947.

15 Hermes-Lima M, Ponka P, Schulman HM. The iron chelator pyridoxal isonicotinoyl hydrazone (PIH) and its analogues prevent damage to 2-deoxyribose mediated by ferric iron plus ascorbate. Biochim Biophys Acta 2000;1523:154-160.

16 Gorczyca W, Gong J, Darzynkiewicz Z. Detection of DNA strand breaks in individual apoptotic cells by the in situ terminal deoxynucleotidyl transferase and nick translation assays. Cancer Res 1993;53:1945-1951.

$17 \mathrm{Wu}$ JC, Merlino G, Fausto N. Establishment and characterization of differentiated, nontransformed hepatocyte cell lines derived from mice transgenic for transforming growth factor alpha. Proc Natl Acad Sci USA 1994;91:674-678.

18 Pierce RH, Campbell JS, Stephenson AB, et al. Disruption of redox homeostasis in tumor necrosis factor-induced apoptosis in a murine hepatocyte cell line. Am J Pathol 2000;157:221-236.

19 Arsura M, FitzGerald MJ, Fausto N, Sonenshein GE. Nuclear factor-kappaB/Rel blocks transforming growth factor beta1-induced apoptosis of murine hepatocyte cell lines. Cell Growth Differ 1997;8:1049-1059.
20 Gottlieb RA, Adachi S. Nitrogen cavitation for cell disruption to obtain mitochondria from cultured cells. Methods Enzymol 2000;322:213-221.

21 Kayagaki N, Yamaguchi N, Nagao F, et al. Polymorphism of murine Fas ligand that affects the biological activity. Proc Natl Acad Sci USA 1997;94: 3914-3919.

22 Yoon JH, Gores GJ. Death receptor-mediated apoptosis and the liver [Review]. J Hepatol 2002;37:400-410.

23 Yin XM, Wang K, Gross A, et al. Bid-deficient mice are resistant to Fas-induced hepatocellular apoptosis. Nature 1999;400:886-891.

24 Zheng TS, Hunot S, Kuida K, et al. Deficiency in caspase-9 or caspase-3 induces compensatory caspase activation. Nat Med 2000;6:1241-1247.

$25 \mathrm{Kim} \mathrm{TH}$, Zhao Y, Barber MJ, et al. Bid-induced cytochrome $C$ release is mediated by a pathway independent of mitochondrial permeability transition pore and Bax. J Biol Chem 2000;275:39474-39481.

26 Hunt A, Evan G. Apoptosis Till death us do part [Letter]. Science 2001;293:1784-1785

27 Faouzi S, Burckhardt BE, Hanson JC, et al. Anti-Fas induces hepatic chemokines and promotes inflammation by an NF-kappa B-independent, caspase-3-dependent pathway. J Biol Chem 2001;276:49077-49082.

28 Madesh M, Antonsson B, Srinivasula SM, et al. Rapid kinetics of tBid-induced cytochrome $c$ and Smac/ DIABLO release and mitochondrial depolarization. J Biol Chem 2002;277:5651-5659.

$29 \mathrm{Li} \mathrm{H}$, Zhu H, Xu CJ, Yuan J. Cleavage of BID by caspase 8 mediates the mitochondrial damage in the Fas pathway of apoptosis. Cell 1998;94:491-501.

30 Tafani M, Karpinich NO, Hurster KA, et al. Cytochrome $c$ release upon Fas receptor activation depends on translocation of full-length bid and the induction of the mitochondrial permeability transition. J Biol Chem 2002;277:10073-10082.

31 Chien MM, Zahradka KE, Newell MK, et al. Fasinduced B cell apoptosis requires an increase in free cytosolic magnesium as an early event. J Biol Chem 1999;274:7059-7066.

32 Patel T, Bronk SF, Gores GJ. Increases of intracellular magnesium promote glycodeoxycholate-induced apoptosis in rat hepatocytes. J Clin Invest 1994;94: 2183-2192.

33 Eskes R, Desagher S, Antonsson B, et al. Bid induces the oligomerization and insertion of Bax into the outer mitochondrial membrane. Mol Cell Biol 2000;20: 929-935.

34 Shi Y, Wang R, Sharma A, et al. Dissociation of cytokine signals for proliferation and apoptosis. J Immunol 1997;159:5318-5328.

35 Schurmann A, Mooney AF, Sanders LC, et al. p21activated kinase 1 phosphorylates the death agonist bad and protects cells from apoptosis. Mol Cell Biol 2000;20:453-461.

36 Kauffmann-Zeh A, Rodriguez-Viciana P, Ulrich E, et al. Suppression of c-Myc-induced apoptosis by Ras signalling through $\mathrm{PI}(3) \mathrm{K}$ and PKB. Nature 1997;385:544-548.

37 Storch S, Kubler B, Honing S, et al. Transferrin binds insulin-like growth factors and affects binding properties of insulin-like growth factor binding protein-3. FEBS Lett 2001;509:395-398.

38 Oh Y, Muller HL, Ng L, Rosenfeld RG. Transforming growth factor-beta-induced cell growth inhibition in human breast cancer cells is mediated through 
insulin-like growth factor-binding protein-3 action. J Biol Chem 1995;270:13589-13592.

39 Trowbridge IS, Lopez F. Monoclonal antibody to transferrin receptor blocks transferrin binding and inhibits human tumor cell growth in vitro. Proc Natl Acad Sci USA 1982;79:1175-1179.

40 Chen LH, Bissell MJ. Transferrin mRNA level in the mouse mammary gland is regulated by pregnancy and extracellular matrix. J Biol Chem 1987;262: 17247-17250.

41 Welch S. A comparison of the structure and properties of serum transferrin from 17 animal species. Comp Biochem Physiol [B] 1990;97:417-427.

42 Lesnikov V, Lesnikova M, Shulman HM, et al. In vivo cytoprotective and immunomodulatory effects of transferrin. Res Adv Blood 2001;1:169-178. 